\title{
Probabilistic Ecological Risk Assessment of OCPs, PCBs, and DLCs in the Haihe River, China
}

\author{
Bin Wang ${ }^{1,2}$, Gang $\mathrm{Yu}^{1, *}$, Jun Huang ${ }^{1}$, Tai Wang ${ }^{1}$, and Hongying $\mathrm{Hu}^{1}$ \\ ${ }^{1}$ Department of Environmental Science and Engineering, POPs Research Centre, \\ Tsinghua University, Beijing, China; ${ }^{2}$ Institute for Sustainability and Peace, United \\ Nations University, Shibuya, Tokyo, Japan \\ E-mail: yg-den@tsinghua.edu.cn \\ Received March 15, 2010; Revised May 16, 2010; Accepted May 22, 2010; Published July 6, 2010
}

The Haihe River is the most seriously polluted river among the seven largest rivers in China. Dichloro-diphenyl-trichloroethanes (DDTs), hexachlorocyclohexanes (HCHs), and PCBs (noncoplanar polychlorinated biphenyls) in the Haihe River, Tianjin were determined using a gas chromatograph - electron capture detector (GC-ECD). Dioxin-like compounds (DLCs) were determined using Chemically Activated LUciferase gene eXpression (CALUX) bioassay. HCH and DDT levels were, respectively, 0.06-6.07 $\mu \mathrm{g} / \mathrm{L}$ and ND (not detected) to $1.21 \mu \mathrm{g} / \mathrm{L}$; PCB levels ranged from 0.12 to $5.29 \mu \mathrm{g} / \mathrm{L}$; and the total DLCs in sediment were 4.78-343 pg TEQ (toxic equivalency)/g. Aquatic ecological risk assessment was performed using the joint probability curve method and the Monte Carlo-based HQ (hazard quotient) distribution method. The combined risks of similar chemicals and the total risk of dissimilar categories of chemicals were assessed based on the principles of joint toxicity. Due to the adjacent industrial activities, the risk levels of PCBs, DDTs, and HCHs were relatively high. The risk order was as follows: PCBs > DDTs $\approx \mathrm{HCHs}>$ DLCs. The risk of HCHs approximated that of DDTs, which is different from the fact that risk of HCHs is usually much lower in the other Chinese rivers. The total risk caused by these pollutants was very high. Due to their high persistence and potential source from land, the high risks of such pollutants are likely to last for a long period of time.

KEYWORDS: ecological risk assessment, organochlorine pesticides, persistent organic pollutants, DDTs, HCHs, PCBs, DLCs, the Haihe River, joint probability curve, Monte Carlobased $\mathrm{HQ}$ distribution

\section{INTRODUCTION}

China, as one of the countries with the largest agricultural production system, was once a major producer and consumer of organochlorine pesticides (OCPs)[1]. From the 1950s to 1980s, the production of dichloro-diphenyl-trichloroethanes (DDTs) and hexachlorocyclohexanes (HCHs) in China was 0.4 and 4.9 million tons, accounting for 20 and $33 \%$ of the total global production, respectively[2]. Polychlorinated biphenyls (PCBs) are another important category of legacy persistent organic pollutants (POPs), whose production in China from 1965 to 1974 was about 10,000 tons[3]. The unintentionally 
produced legacy POPs, polychlorinated dibenzo-p-dioxins and furans (PCDD/Fs), have been poorly characterized in the environmental matrices in China due to limited instrumentation and trained personnel[4]. The annual dioxin release in China was estimated to be about $10 \mathrm{~kg}$ TEQ (toxic equivalents)[5]. Recently, Chemically Activated LUciferase gene eXpression (CALUX) bioassay has been used to determine the PCDD/F pollution in China[6,7]. Compared with the high-resolution gas chromatography/high-resolution mass spectrometry (HRGC/HRMS) method, CALUX is a faster and cheaper method that can provide a comprehensive measure of the aryl hydrocarbon receptor activity and potential hazard[8].

The Haihe River, the largest water body in North China, is $1,329 \mathrm{~km}$ long from the longest tributary. It is formed by more than 300 tributaries and converges near Tianjin City to form the 70-km trunk of the Haihe River, which then flows into Bohai Bay. The average annual water flow of the Haihe River is $2.1 \times$ $10^{10} \mathrm{~m}^{3}$. The Haihe River is the most badly polluted river among the seven largest rivers in China[9]. As an important chemical industry city in China, Tianjin has produced huge amounts of OCPs, such as technical $\mathrm{HCH}$, lindane, DDT, chlorobenzene, as well as pentachlorophenol (PCP) and its sodium salt (PCP-Na) for a long period of time[10,11]. PCBs have also been used in Tianjin to produce paints. Chlorinated chemicals, such as PCP and PCP-Na, have been identified as an important source of dioxin release[12,13,14]. The local flourishing chloralkli industry may also unintentionally produce dioxin-like compounds (DLCs)[15].

Although the Haihe River may have been badly polluted by such pollutants, their potential ecological risks have not been well addressed. The conventional method of ecological risk assessment (ERA) is a deterministic approach, such as the hazard quotient (HQ) method, which is suitable for preliminary screening-stage risk assessment. However, it cannot account for the spatial and temporal variability of exposure levels as well as the probability of ecological effects. As an alternative, probabilistic risk assessment, such as the joint probability curve (JPC) method and the Monte Carlo-based HQ distribution method, can provide a quantitative description of the distribution and possibility of ecological risks posed by pollutants in the environment $[16,17]$. The aquatic ecosystem is usually exposed to mixtures of similar or dissimilar chemicals. The risk caused from the exposures to multiple chemicals should also be cautioned.

This study aims to use probabilistic options to refine the aquatic ERA of various POPs (including OCPs, PCBs, and DLCs) in the Haihe River, China. The risks to aquatic species were assessed using information on their experimentally determined concentration data and reported toxicity values. The combined risks of similar chemicals and the total risk of dissimilar categories of chemicals were assessed based on the principles of joint toxicity. This study can contribute to the risk management of such pollutants.

\section{MATERIALS AND METHODS}

\section{Sampling and Analysis of the POPs}

\section{Sampling}

The sampling sites (Fig. 1) spread from $117^{\circ} 11.00^{\prime} \mathrm{E}$ to $117^{\circ} 48.50^{\prime} \mathrm{E}$, and from $38^{\circ} 58.10^{\prime} \mathrm{N}$ to $39^{\circ} 07.83^{\prime}$ N. Water samples were taken twice, in August 2004 and March 2005, for OCP and PCB analysis. Sediment samples were also taken twice, in March 2005 and November 2006, for DLC analysis. The mass fraction of organic carbon contents $\left(f_{\text {oc }}\right)$ of the sediment samples were determined according to the national standard method of China[18]. 


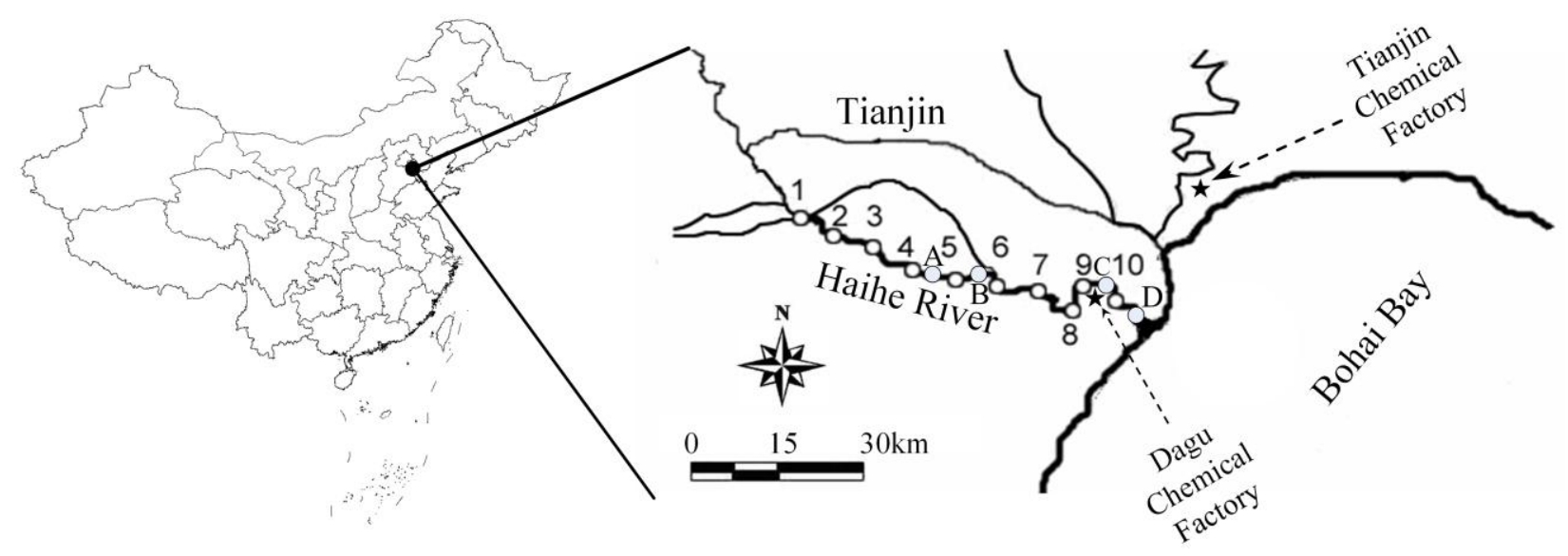

FIGURE 1. Sampling sites in the Haihe River. Water and sediment samples were taken from Sites 1-10. Four additional water samples were taken from sites A, B, C, and D in March 2005.

\section{OCP and PCB Analysis[19]}

OCP and PCB analysis was conducted following USEPA method 8081B and USEPA method 8082A, respectively. Water samples were filtered through a glass fiber filter (Millipore, 47-mm diameter, 0.7- $\mu \mathrm{m}$ nominal cutoff). Decabromobiphenyl (PCB209, $0.2 \mu \mathrm{g}$ ) was added to water samples as an internal standard. Then, water samples were passed through the Supelclean ENVI-18 solid-phase extraction (SPE) cartridges at a flow rate of $5 \mathrm{~mL} / \mathrm{min}$. Following extraction, the cartridges were freeze dried and eluted with $15 \mathrm{~mL}$ of ethyl acetate. The effluents were concentrated to $1.0 \mathrm{~mL}$ for the gas chromatograph electron capture detector (GC-ECD) (Agilent 6890; Agilent Technologies, USA) analysis. The statistical summary of their concentrations are listed in Table 1 . If the concentrations were below the limit of detection (LOD), namely ND (not detected), random values were selected at the interval[0, LOD] to substitute for ND, assuming a uniform distribution.

\section{DLC Analysis[6]}

DLC analysis was conducted following USEPA method 4435. The sediment samples were freeze dried, milled, and passed through a 60-mesh sieve; $3.50 \mathrm{~g}$ of sediment samples were extracted with methanol/toluene $(1: 4, \mathrm{v} / \mathrm{v})$, cleaned up by a $25-\mathrm{mL}$ celite column, and a $25-\mathrm{mL}$ sulfuric acid silica gel column, and then separated on a 5-mL disposable X-CARB (Xenobiotic Detection Systems, USA) column into PCDD/Fs fraction and DL-PCBs fraction. H1L6.1c2 cells were exposed to the fractions in 96-well plates. RLU (relative light unit) was then measured by the microplate luminometer (Berthold Centro LB 960, Germany). The calibration curve was used to convert the measured RLU values into CALUX TEQ values expressed in pg TEQ/g dw (dry weight) sediment. HRGC (Agilent 6890N)/HRMS (JEOL JMS-800D, Japan) analysis was also conducted to make validation. Ten 2,3,7,8-substitute PCDFs, seven 2,3,7,8-substitute PCDDs, and 12 DL-PCBs were determined. A good correlation between CALUX results and HRGC/HRMS results was observed. The water concentrations $\left(\mathrm{C}_{\text {water }}\right)$ of DLCs were estimated from CALUX TEQs in sediment $\left(\mathrm{C}_{\mathrm{sed}}\right)$ based on the equilibrium partitioning method[20]:

$$
\mathrm{C}_{\text {water }}(\mathrm{pg} \mathrm{TEQ} / \mathrm{L})=\mathrm{C}_{\text {sed }}(\mathrm{pg} \mathrm{TEQ} / \mathrm{kg}) / \mathrm{K}_{\mathrm{p}}=\mathrm{C}_{\text {sed }}(\mathrm{pg} \mathrm{TEQ} / \mathrm{kg}) \cdot f_{\mathrm{oc}} / \mathrm{K}_{\mathrm{oc}}
$$

where $\mathrm{K}_{\mathrm{p}}$ is the partition coefficient between the solid and the aqueous phase; $\mathrm{L} / \mathrm{kg} ; \mathrm{K}_{\mathrm{oc}}$ is the partition coefficient normalized by organic carbon content. 
TABLE 1

Statistical Summary of Species Toxicity Data of the Studied POPs and Their Concentrations in the Haihe River

\begin{tabular}{|c|c|c|c|c|c|c|}
\hline & \multirow{2}{*}{ Compound } & \multicolumn{5}{|c|}{ Statistical Summary } \\
\hline & & $\mathbf{n}$ & Min & Max & Geometric Mean & Geometric SD \\
\hline \multirow[t]{8}{*}{ Toxicity data ( $\mu \mathrm{g} / \mathrm{L})$} & $p, p^{\prime}-D D T$ & 207 & 0.10 & $1,634,840$ & 96.95 & 19.66 \\
\hline & $p, p^{\prime}-D D E$ & 10 & 1.55 & 123,173 & 124.61 & 32.85 \\
\hline & $p, p^{\prime}-D D D$ & 25 & 0.29 & 22,200 & 46.59 & 17.19 \\
\hline & $\alpha-\mathrm{HCH}$ & 18 & 120 & 24,000 & 1938.30 & 5.38 \\
\hline & $\mathrm{Y}-\mathrm{HCH}^{\mathrm{a}}$ & 145 & 2.00 & $3,926,205$ & 278.44 & 14.73 \\
\hline & $\delta-\mathrm{HCH}$ & 39 & 6.90 & 100,000 & 683.05 & 13.34 \\
\hline & PCBs & 37 & 0.53 & 38,725 & 112.80 & 18.34 \\
\hline & 2,3,7,8-TCDD & 13 & 0.0017 & 30 & 0.68 & 20.99 \\
\hline \multirow[t]{10}{*}{ Concentration $(\mu \mathrm{g} / \mathrm{L})$} & p,p'-DDT & 24 & ND & 1.05 & 0.0052 & 80.61 \\
\hline & $p, p^{\prime}-D D E$ & 24 & ND & 0.16 & $2.56 \times 10^{-4}$ & 77.60 \\
\hline & $p, p^{\prime}-D D D$ & 24 & ND & 0.053 & $1.49 \times 10^{-4}$ & 91.38 \\
\hline & $\mathrm{DDTs}^{\mathrm{b}}$ & 24 & ND & 1.16 & 0.020 & 38.97 \\
\hline & $\alpha-\mathrm{HCH}$ & 24 & 0.0079 & 2.72 & 0.10 & 4.07 \\
\hline & $\mathrm{y}-\mathrm{HCH}^{\mathrm{a}}$ & 24 & 0.043 & 2.13 & 0.22 & 2.68 \\
\hline & $\delta-\mathrm{HCH}$ & 24 & 0.0077 & 1.23 & 0.11 & 3.38 \\
\hline & $\mathrm{HCHs}^{\mathrm{C}}$ & 24 & 0.050 & 3.02 & 0.29 & 2.80 \\
\hline & PCBs & 24 & 0.12 & 5.29 & 0.59 & 2.70 \\
\hline & DLCs ${ }^{d}$ & 20 & 4.78 & 343.25 & 35.29 & 3.88 \\
\hline
\end{tabular}

a $\gamma-\mathrm{HCH}$ and $\beta-\mathrm{HCH}$ were merged into $\mathrm{y}-\mathrm{HCH}$ to perform ERA due to the lack of toxicity data of $\beta-\mathrm{HCH}$.

b DDTs value is the total equivalent concentration of DDTs to $p, p^{\prime}-D D T$.

c $\mathrm{HCH}$ salue is the total equivalent concentration of $\mathrm{HCHs}$ to $\mathrm{y}-\mathrm{HCH}$.

d The unit is $\mathrm{pg} T E Q / g$.

\section{Ecological Risk Assessment of the POPs}

\section{Toxicity Data}

Toxicity data (half lethal concentration, $\mathrm{LC}_{50}$ ) of DDTs, HCHs, PCBs, and 2,3,7,8-PCDD for aquatic species in various trophic levels were mainly extracted from Aquatic Information Retrieval of the USEPA (AQUIRE, http://www.epa.gov/ecotox). Species sensitivity distributions (SSDs) were constructed by developing cumulative probability distributions of logarithmically transformed $\mathrm{LC}_{50}[21]$. For each species, if more than one toxicity datum was available, the average was taken to develop SSDs. The species toxicity data are summarized in Table 1.

\section{JPC Method}

The Kolmogorov-Smirnov test showed that the lognormal model was generally applicable for fitting the spatial and temporal distribution of the concentrations of these pollutants in the Haihe River. Therefore, the lognormal model was used to fit the exposure concentrations to generate the exposure concentration 
distributions (ECDs). A JPC was generated from aquatic ECD and SSD[22]. The overall risk was usually illustrated qualitatively by the adjacence degree of the curve to axes. In this study, the overall risk probability (ORP) was introduced to characterize the overall ecological risk quantitatively:

$$
\mathrm{ORP}=\int_{0}^{1} \operatorname{EPr}(\mathrm{x}) \mathrm{dx}
$$

where $\operatorname{EPr}(\mathrm{x})$ is the exceedance probability for $\mathrm{x}$ proportion of species affected $(0 \leq \mathrm{x} \leq 1)$. ORP could also be calculated as the area under the JPC. Because sufficient chronic toxicity data, such as no observed effect concentrations (NOECs), were unavailable, SSDs were developed based on a set of "surrogate NOECs" generated by dividing acute toxicity values $\left(\mathrm{LC}_{50}\right)$ by a set of ACRs (acute to chronic ratio) (1, $5,25,125$, and 1000). A series of JPCs and corresponding ORPs was achieved[22].

\section{Monte Carlo-Based HQ Distribution Method}

HQ was defined as follows:

$$
\mathrm{HQ}=\mathrm{EEC} / \mathrm{LC}_{50}
$$

where EEC is environmental exposure concentration. The HQ distribution was generated from ECD and LC $_{50}$-based SSD after 20,000-times Monte Carlo simulation using Matlab v7.0. Risk was then expressed as the probability of exceeding certain HQ criteria $(1,1 / 5,1 / 25,1 / 125,1 / 1000)$ corresponding to a series of ACRs mentioned above[22].

\section{RESULTS AND DISCUSSION}

\section{Pollution Status of the POPs}

In the Haihe River, $\mathrm{HCH}$ levels (including $\alpha-\mathrm{HCH}, \beta-\mathrm{HCH}, \gamma-\mathrm{HCH}$, and $\delta-\mathrm{HCH}$ ) were $0.30-1.07 \mu \mathrm{g} / \mathrm{L}$ in August 2004 and 0.06-6.07 $\mu \mathrm{g} / \mathrm{L}$ in March 2005. DDT levels (including p,p'-DDT, p,p'-DDD, and p,p'DDE) were ND to $0.15 \mu \mathrm{g} / \mathrm{L}$ in August 2004 and $0.04-1.21 \mu \mathrm{g} / \mathrm{L}$ in March 2005. HCH levels were generally higher than DDT levels. Total PCB levels ranged from 0.31 to $3.12 \mu \mathrm{g} / \mathrm{L}$ in August 2004 and from 0.12 to $5.29 \mu \mathrm{g} / \mathrm{L}$ in March 2005. The DLC levels (including PCDD/Fs and DL-PCBs) in sediment were 4.78-343 and 5.44-324 pg TEQ/g in March 2005 and November 2006, respectively. PCDD/Fs were the main contributor to the total TEQs, which contributed more than 97\% of the total TEQs. Compared with the other rivers in China and worldwide, the levels of such POPs were realtively high in the Haihe River. The highest levels occurred at its downstream area (Sites 9 and 10), which was near the chemical industrial area. The Dagu Chemical factory, located near Sites 9 and 10, was the only legal $\mathrm{HCH}$ and lindane producer in China after 1983, and it produced HCHs or lindane until 1999. The Tianjin Chemical factory, as one of the two legal DDT producers in China, produced DDTs until May 2009. PCBs had been used to produce paint at the Tianjin Paint factory, the largest paint factory in China. PCBs can also be released into the water body from the painted ships in the Haihe River and the adjacent Bohai Bay. The PCPs and PCP-Na had been manufactured for a long period of time at the Dagu Chemical factory. It is sure that these industrial sources contributed a lot to the heavy pollution of these POPs. 


\section{Ecological Risk of OCPs}

\section{Ecological Risk of Single OCPs}

The results of the Monte Carlo-based HQ distribution method are shown in Table 2. From the geometric mean of HQ, it can be seen that the risk of $\gamma-\mathrm{HCH}$ ranked first among the OCPs in the Haihe River. The risk order was $\gamma-\mathrm{HCH}>\delta-\mathrm{HCH}>\mathrm{p}, \mathrm{p}^{\prime}-\mathrm{DDT}>\alpha-\mathrm{HCH}>\mathrm{p}, \mathrm{p}^{\prime}-\mathrm{DDD}>\mathrm{p}, \mathrm{p}^{\prime}-\mathrm{DDE}$. However, according to the probabilities of exceeding a HQ criterion of $1 / 25$, the risk order was p,p'-DDT $>\gamma$-HCH $>$ p,p'-DDD > $\mathrm{p}, \mathrm{p}^{\prime}-\mathrm{DDE}>\delta-\mathrm{HCH}>\alpha-\mathrm{HCH}$. The risk order seemed to be different based on different evaluation indicators. The reason might be the different meanings between the geometric mean of HQ and risk probabilities of exceeding a HQ criterion of $1 / 25$. The former is the statistical value of the results of Monte Carlo simulation, regardless of whether HQ is higher or lower than HQ criteria. The latter reflects the part of HQs that may cause potential risk. Risk probability based on such a specific criterion is more risk-meaningful. The ecological risk probabilities also differ a lot based on different HQ criteria. Too loose an ecological protection level $(\mathrm{HQ}=1)$ may cause negligence of risk, and no measure will be taken to reduce the existing risk. On the contrary, risk may be overestimated at a too rigorous ecological protection level $(\mathrm{HQ}=1 / 1000)$. In order to minimize the risk to a too rigorous criterion, massive manpower, material, and financial resources may be wasted on overprotective measures. Although chronic toxicity data are preferable in ERA, a HQ of $1 / 25$ is a suitable approximate ecological protection level when chronic toxicity data of species are scarce and $\mathrm{LC}_{50} \mathrm{~s}$ are used to develop SSD.

TABLE 2

The Results from the Monte Carlo-Based HQ Distribution Method

\begin{tabular}{lcccccc}
\hline \multirow{2}{*}{ Compound } & \multirow{2}{*}{$\begin{array}{c}\text { Geometric } \\
\text { Mean of HQ }\end{array}$} & \multicolumn{5}{c}{ Probability of Exceeding Preselected HQ Criteria } \\
\cline { 3 - 7 } & & $\mathbf{1}$ & $\mathbf{1 / 5}$ & $\mathbf{1 / 2 5}$ & $\mathbf{1 / 1 2 5}$ & $\mathbf{1 / 1 0 0 0}$ \\
\hline$\alpha-\mathrm{HCH}$ & $5.43 \times 10^{-5}$ & $3.75 \times 10^{-6}$ & $9.02 \times 10^{-5}$ & $1.30 \times 10^{-3}$ & $1.14 \times 10^{-2}$ & $9.20 \times 10^{-2}$ \\
$\mathrm{y}-\mathrm{HCH}$ & $7.76 \times 10^{-4}$ & $6.60 \times 10^{-3}$ & $2.74 \times 10^{-2}$ & $8.62 \times 10^{-2}$ & $2.10 \times 10^{-1}$ & $4.65 \times 10^{-1}$ \\
$\delta-\mathrm{HCH}$ & $1.67 \times 10^{-4}$ & $1.16 \times 10^{-3}$ & $6.53 \times 10^{-3}$ & $2.75 \times 10^{-2}$ & $8.76 \times 10^{-2}$ & $2.65 \times 10^{-1}$ \\
p,p'-DDT & $5.67 \times 10^{-5}$ & $4.28 \times 10^{-2}$ & $7.55 \times 10^{-2}$ & $1.24 \times 10^{-1}$ & $1.92 \times 10^{-1}$ & $3.07 \times 10^{-1}$ \\
p,p'-DDE & $1.79 \times 10^{-6}$ & $1.07 \times 10^{-3}$ & $2.16 \times 10^{-2}$ & $4.07 \times 10^{-2}$ & $7.18 \times 10^{-2}$ & $1.36 \times 10^{-1}$ \\
p,p'-DDD & $3.07 \times 10^{-6}$ & $9.84 \times 10^{-3}$ & $2.08 \times 10^{-2}$ & $4.08 \times 10^{-2}$ & $7.42 \times 10^{-2}$ & $1.44 \times 10^{-1}$ \\
HCHs & $1.00 \times 10^{-3}$ & $7.99 \times 10^{-3}$ & $3.25 \times 10^{-2}$ & $9.99 \times 10^{-2}$ & $2.36 \times 10^{-1}$ & $5.04 \times 10^{-1}$ \\
DDTs & $2.08 \times 10^{-4}$ & $3.46 \times 10^{-2}$ & $7.04 \times 10^{-2}$ & $1.30 \times 10^{-1}$ & $2.17 \times 10^{-1}$ & $3.68 \times 10^{-1}$ \\
PCBs & $5.37 \times 10^{-3}$ & $4.44 \times 10^{-2}$ & $1.19 \times 10^{-1}$ & $2.56 \times 10^{-1}$ & $4.47 \times 10^{-1}$ & $7.06 \times 10^{-1}$ \\
DLCs & $1.32 \times 10^{-5}$ & $3.56 \times 10^{-4}$ & $1.87 \times 10^{-3}$ & $7.86 \times 10^{-3}$ & $2.68 \times 10^{-2}$ & $9.62 \times 10^{-2}$ \\
Total & & $8.51 \times 10^{-2}$ & $2.09 \times 10^{-1}$ & $4.21 \times 10^{-1}$ & $6.78 \times 10^{-1}$ & $9.17 \times 10^{-1}$ \\
\hline
\end{tabular}

The ORPs at various ACRs in the JPC method (Table 3) approximated the probabilities of exceeding the corresponding HQ criteria (Table 2). According to the ORPs at an ACR of 25, the risks of p,p'-DDT and $\gamma-\mathrm{HCH}$ were the highest in the Haihe River, while the risk of $\alpha-\mathrm{HCH}$ was the lowest. ORPs calculated at the ACR of 5 and 125 could be respectively considered as the lower limit and higher limit of ORPs calculated at the ACR of 25 . The ORPs would be underestimated if $\mathrm{LC}_{50}$ were directly used to develop the JPC $(A C R=1)$ and overestimated if ACR was set as 1000 . 
TABLE 3

ORPs Calculated from JPCs

\begin{tabular}{lccccc}
\hline \multirow{2}{*}{ Compound } & \multicolumn{5}{c}{ ORPs at Various ACRs } \\
\cline { 2 - 6 } & $\mathbf{1}$ & $\mathbf{5}$ & $\mathbf{2 5}$ & $\mathbf{1 2 5}$ & $\mathbf{1 0 0 0}$ \\
\hline $\mathrm{a}-\mathrm{HCH}$ & $3.55 \times 10^{-6}$ & $8.63 \times 10^{-5}$ & $1.26 \times 10^{-3}$ & $1.11 \times 10^{-2}$ & $9.04 \times 10^{-2}$ \\
Y-HCH & $6.41 \times 10^{-3}$ & $2.70 \times 10^{-2}$ & $8.61 \times 10^{-2}$ & $2.11 \times 10^{-1}$ & $4.69 \times 10^{-1}$ \\
D-HCH & $1.20 \times 10^{-3}$ & $6.67 \times 10^{-3}$ & $2.79 \times 10^{-2}$ & $8.85 \times 10^{-2}$ & $2.66 \times 10^{-1}$ \\
p,p'-DDT & $4.35 \times 10^{-2}$ & $7.62 \times 10^{-2}$ & $1.25 \times 10^{-1}$ & $1.92 \times 10^{-1}$ & $3.06 \times 10^{-1}$ \\
p,p'-DDE & $1.02 \times 10^{-2}$ & $2.08 \times 10^{-2}$ & $3.96 \times 10^{-2}$ & $7.04 \times 10^{-2}$ & $1.34 \times 10^{-1}$ \\
p,p'-DDD & $9.74 \times 10^{-3}$ & $2.07 \times 10^{-2}$ & $4.08 \times 10^{-2}$ & $7.42 \times 10^{-2}$ & $1.44 \times 10^{-1}$ \\
HCHs & $8.57 \times 10^{-3}$ & $3.40 \times 10^{-2}$ & $1.03 \times 10^{-1}$ & $2.40 \times 10^{-1}$ & $5.06 \times 10^{-1}$ \\
DDTs & $3.66 \times 10^{-2}$ & $7.34 \times 10^{-2}$ & $1.33 \times 10^{-1}$ & $2.21 \times 10^{-1}$ & $3.71 \times 10^{-1}$ \\
PCBs & $4.40 \times 10^{-2}$ & $1.18 \times 10^{-1}$ & $2.55 \times 10^{-1}$ & $4.46 \times 10^{-1}$ & $7.06 \times 10^{-1}$ \\
DLCs & $3.61 \times 10^{-4}$ & $1.90 \times 10^{-3}$ & $8.02 \times 10^{-3}$ & $2.73 \times 10^{-2}$ & $9.80 \times 10^{-2}$ \\
Total & $8.71 \times 10^{-2}$ & $2.12 \times 10^{-1}$ & $4.25 \times 10^{-1}$ & $6.81 \times 10^{-1}$ & $9.18 \times 10^{-1}$ \\
\hline & & & & & \\
\hline
\end{tabular}

\section{Combined Risk of DDTs and HCHs}

For similar compounds, the joint toxicity mechanism is usually concentration addition[23,24,25,26]. Thus, total equivalent concentration of the DDTs or HCHs was calculated according to the concept of concentration addition:

$$
\mathrm{C}_{\text {equ,tol }}=\sum_{\mathrm{i}=1}^{\mathrm{n}} \mathrm{C}_{\text {equ, }}=\sum_{\mathrm{i}=1}^{\mathrm{n}} \mathrm{C}_{\mathrm{i}} \times \frac{\mathrm{LC}_{50 \text { ref,geomean }}}{\mathrm{LC}_{50 \mathrm{i}, \text { geomean }}}
$$

where $\mathrm{C}_{\mathrm{i}}$ is the aquatic concentration of compound $\mathrm{i}$; $\mathrm{LC}_{50 \mathrm{i} \text {,geomean }}$ and $\mathrm{LC}_{50 \text { ref,geomean }}$ are, respectively, the geometric mean of $\mathrm{LC}_{50}$ of compound $\mathrm{i}$ and the reference compound. In this study, p,p'-DDT was used as the reference compound for DDTs; $\gamma-\mathrm{HCH}$ was used as the reference compound for HCHs. According to the distribution of $\mathrm{C}_{\text {equ,tol }}$ and SSD of the reference compound, the combined ecological risks of DDTs and HCHs were assessed by the JPC and HQ distribution methods.

Combined HQ distributions of DDTs and HCHs in the Haihe River are shown in Fig. 2A,B. The geometric means of combined HQs of HCHs and DDTs in the Haihe River were, respectively, $1.00 \times 10^{-3}$ and $2.08 \times 10^{-4}$. The risk probabilities of exceeding a HQ criterion of $1 / 25$ were, respectively, $9.99 \times 10^{-2}$ and $1.30 \times 10^{-1}$ (Table 3). JPCs of DDTs and HCHs in the Haihe River are shown in Fig. 3A,B. The stricter the risk criteria (the larger the ACRs), the higher the calculated risk (the more distance between the curve and the coordinate axis). Fig. 3 shows that the risk level of DDTs was higher than that of HCHs when a stricter criterion was applied; while the risk level of DDTs was less than that of HCHs when a looser criterion was applied. This indicates that the risk criterion cannot only influence the absolute values of risk, but also influences the relative risk order of the pollutants when their risks approximate each other. For the other water bodies in China, the ecological risk of DDTs is usually higher than that of $\mathrm{HCHs}$ [27], which is mainly because the aquatic toxicity of DDTs is much higher than that of HCHs[21]. However, in the Haihe River, the ecological risk of HCHs was close to or even higher than that of DDTs. The main reason is that the Dagu Chemical factory (Fig. 1) was the only legal HCH and lindane producer in China after 1983, and the $\mathrm{HCH}$ release from the factory contributed to its high risk levels in the Haihe River. 


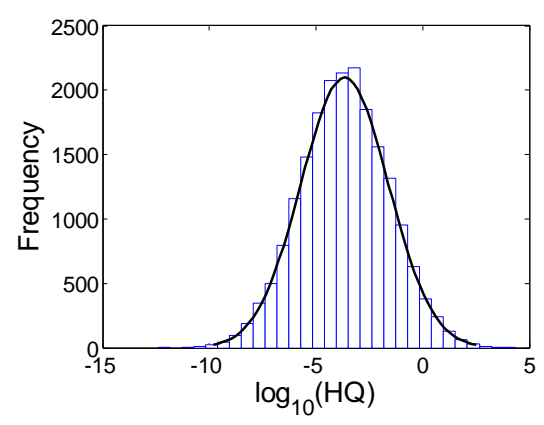

(A) DDTs

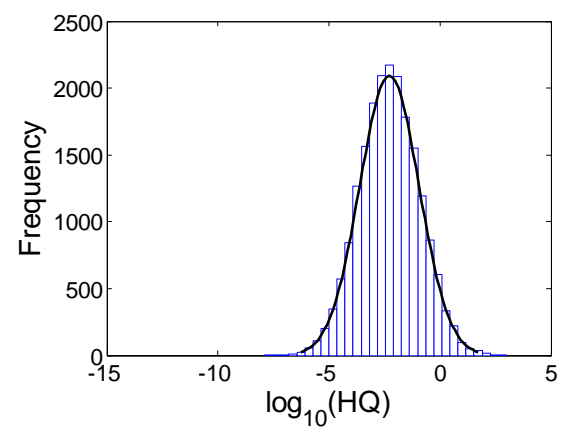

(C) PCBs

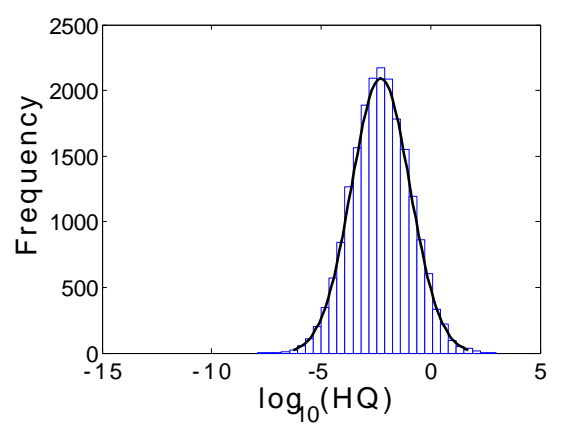

(B) $\mathrm{HCHs}$

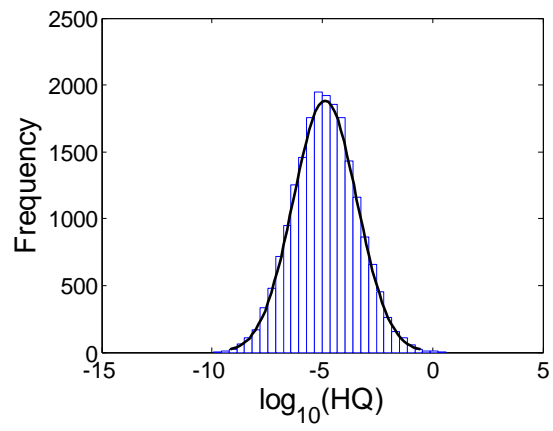

(D) DLCs

FIGURE 2. Combined HQ distributions of DDTs, HCHs, PCBs, and DLCs in the Haihe River.

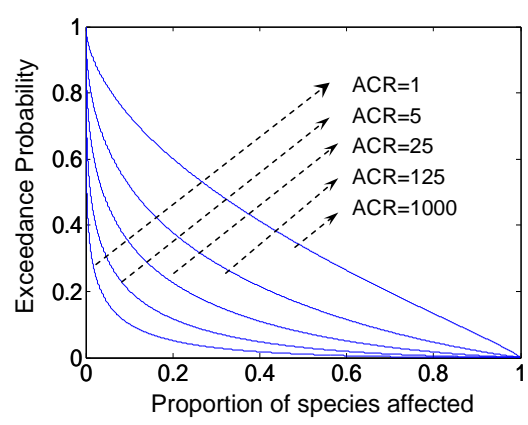

(A) DDTs

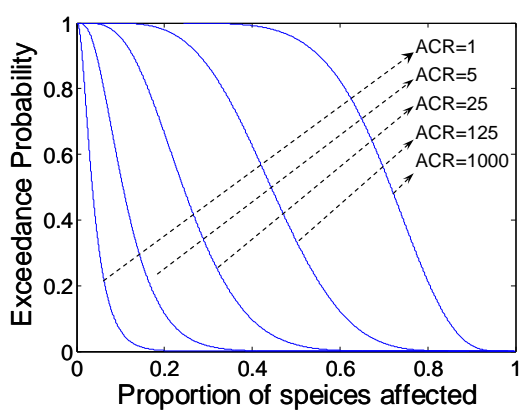

(C) PCBs

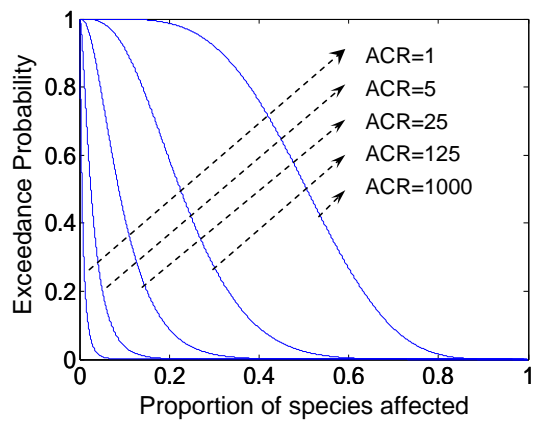

(B) $\mathrm{HCHs}$

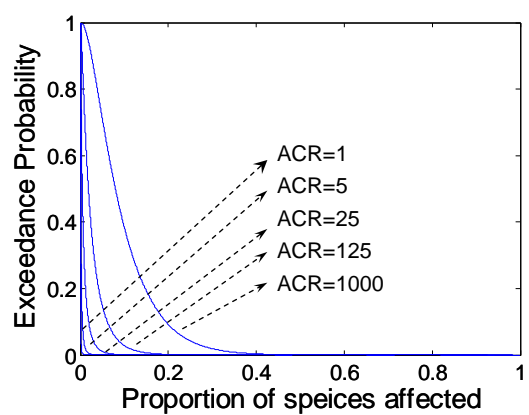

(D) DLCs

FIGURE 3. JPCs of DDTs, HCHs, PCBs, and DLCs in the Haihe River. 
The combined risks caused by the DDTs or HCHs were significantly higher than the risks of individual chemicals due to their joint action. The joint toxicity mechanism of a mixture composed of similarly acting chemicals is usually concentration addition[23,24,25,26]. In the Haihe River, various similarly acting chemicals coexist, the fractional toxicities of the components remain, and concentration addition effect of the individual components will contribute to the higher combined ecological risk.

\section{Ecological Risk of PCBs and DLCs}

In this study, the risks of individual components of PCBs and DLCs were not assessed due to the lack of enough toxicity data for individual components. The combined risk of PCBs and DLCs are illustrated in Figs. 2 and 3. Table 3 shows that ORPs differed largely for different ACRs. The ORPs calculated at an ACR of 25 were $2.55 \times 10^{-1}$ for PCBs and $8.02 \times 10^{-3}$ for DLCs. The risk of PCBs was higher than that of HCHs and DDTs, while the risk of DLCs was much lower than that of HCHs and DDTs. For PCBs and DLCs, the risk probabilities of exceeding the preselected HQ criteria (Table 2) were also very close to the ORPs at the corresponding ACRs (Table 3). Thus, the same conclusion could be drawn from the HQ distribution method and from the JPC method. They are just the different risk characterization modes with the same essence. However, the JPC method excels the HQ method in its ability to estimate probabilities for different proportions of species affected at various ACRs.

\section{Total Risk of the POPs}

In the Haihe River, the risks of PCBs, $\mathrm{HCHs}$, and DDTs were relatively high, compared with the other water bodies in China[27]. Generally, the risk order was as follows: PCBs > HCHs $\approx$ DDTs > DLCs. For different categories of similarly acting compounds (DDTs, HCHs, PCBs, and DLCs), it was assumed that the joint toxicity mechanism is independent action[28]. Thus, the independent action principle of joint toxicity was introduced to solve the ERA of dissimilar categories of chemicals:

$$
R=1-\prod_{i=1}^{n}\left(1-R_{i}\right)
$$

where $R_{\mathrm{i}}$ indicates the ecological risk of a category of similarly acting compounds (DDTs, HCHs, PCBs, or DLCs).

Tables 2 and 3 show that the total risk caused by these POPs was very high. The high risk was certainly related to the past industrial activities near the Haihe River. Fortunately, in Tianjin, DDT production stopped in 2009 and $\mathrm{HCH}$ production stopped in 1999. The production of PCP and PCP-Na stopped in 2004. PCBs were also forbidden from being used in the paints. The control of these chlorinated industries can also reduce the unintentional generation of DLCs. However, it was found that DDT and PCB levels in the adjacent marine environment increased in 2006, compared with those in 2005[29]. This indicates that the risk of such legacy POPs still should be cautioned against due to their high levels in the surrounding land-soil matrices[30]. Rainfall and the subsequent surface runoff can bring them from landsoil into the water body. The use of dicofol may also bring a new DDT pollution source[31]. The DDTand PCB-containing antifouling paints used for boats in the Haihe River can also be an important source of DDT and PCB pollution. In the U.S., the release of PCBs increased by 2.3 million pounds (over 120\%) in 2008, due to the removal of PCBs from service and then sent for disposal[32]. In China, there are a large number of PCB-containing facilities sealed at some sites for safekeeping. More attention should be paid to the risk of PCB release to the ambient environment from these stockpile sites or during the PCB disposal process. 
Uncertainty still remains even though probabilistic methods are used in ERA. The uncertainty is associated with variability in ecosystem stressors, exposure data, species effect data, risk characterization model, and lack of knowledge[33]. Despite the inherent uncertainties in current risk assessment, the screening for high-risk pollutants would help to decide the allocation of limited manpower, material, and financial resources to priority risk problems.

\section{CONCLUSIONS}

This work determined DDTs, HCHs, PCBs, and DLCs in the Haihe River, and probabilistic approaches were used to analyze their potential ecological risks. The results from Monte Carlo-based HQ distribution and the JPC method were consistent with each other. Due to industrial activities, their pollution levels and risk levels were high. The combined risks caused by DDTs and HCHs were significantly higher than that of individual OCPs due to their joint action. Generally, in the Haihe River, the risk order was as follows: PCBs $>\mathrm{HCHs} \approx \mathrm{DDTs}>$ DLCs. The total ecological risk of such POPs was very high. With the prohibition of usage and production of the related chlorinated chemicals, it is anticipated that the risk levels will be reduced in the far future. However, the risk caused by such POPs may still exist for a long period due to their high persistence and potential sources from land. Further monitoring and risk assessment is still merited.

\section{ACKNOWLEDGMENT}

This work was supported by the Chinese National Natural Science Fund for the Distinguished Young Scholars (No. 50625823) and the National Basic Research Program of China (No. 2003CB415007).

\section{REFERENCES}

1. Wong, M.H., Leung, A.O.W., Chan, J.K.Y., and Choi, M.P.K. (2005) A review on the usage of POP pesticides in China, with emphasis on DDT loadings in human milk. Chemosphere 60, 740-752.

2. Hua, X. and Shan, Z. (1996) The production and application of pesticides and factor analysis of their pollution in environment in China. Adv. Environ. Sci. 4, 33-45. [Chinese]

3. Xing, Y., Lu, Y.L., Dawson, R.W., Shi, Y.J., Zhang, H., Wang, T.Y., Liu, W.B., and Ren, H.C. (2005) A spatial temporal assessment of pollution from PCBs in China. Chemosphere 60, 731-739.

4. UNEP (2002) Regionally Based Assessment of Persistent Toxic Substances: Central and North East Asia Regional Report. Global Environmental Facility, UNEP-Chemicals, Gevena.

5. SEPA (2007a) The People's Republic of China National Implementation Plan for the Stockholm Convention on Persistent Organic Pollutants. Beijing, China.

6. Wang, B., Yu, G., Zhang, T.T., Huang, J., Wang, T., Nakamura, M., Handa, H., Huang, C.C., and Murata, H. (2009) CALUX bioassay of dioxin like compounds in sediment from the Haihe River, China. Soil Sed. Contam. 18, 397-411.

7. Zhang, T.T., Yu, G., Wang, B., Fiedler, H., Huang, J., and Deng, S.B. (2009) Bioanalytical characterization of dioxinlike activity in sewage sludge from Beijing, China. Chemosphere 75, 649-653.

8. Windal, I., Denison, M.S., Birnbaum, L.S., Van Wouwe, N., Baeyens, W., and Goeyens, L. (2005) Chemically activated luciferace gene expression (CALUX) cell bioassay analysis for the estimation of dioxin-like activity: critical parameters of the CALUX procedure that impact assay results. Environ. Sci. Technol. 39, 7357-7364.

9. SEPA (2007b) Communiqué of Environmental Quality in China in 2006. Beijing, China.

10. Gong, Z.M., Xu, F.L., Dawson, R., Cao, J., Liu, W.X., Li, B.G., Shen, W.R., Zhang, W.J., Qin, B.P., Sun, R., and Tao, S. (2004) Residues of hexachlorocyclohexane isomers and their distribution characteristics in soils in the Tianjin area, China. Arch. Environ. Contam. Toxicol. 46, 432-437.

11. Hu, J.Y., Wan, Y., Shao, B., Jin, X.H., An, W., Jin, F., Yang, M., Wang, X.J., and Sugisaki, M. (2005) Occurrence of trace organic contaminants in Bohai Bay and its adjacent Nanpaiwu River, North China. Mar. Chem. 95, 1-13.

12. Bao, Z.C., Wang, K.O., Kang, J.X., and Zhao, L.W. (1995) Analysis of polychlorinated dibenzo-p-dioxins and polychlorinated dibenzofurans in pentachlorophenol and sodium pentachlorophenate. Environ. Chem. 14, 317-321. [Chinese] 
13. Zheng, M.H., Bao, Z.C., Wang, K.O., Yang, H., and Xu, X.B. (1997) Polychlorinated dibenzo-p-dioxins and dibenzofurans in lake sediments from Chinese schistosomiasis areas. Bull. Environ. Contam. Toxicol. 59, $653-656$.

14. Xu, Y., Zhang, Q.H., Wu, W.Z., and Li, W. (2000) Patterns and levels of PCDD/F in a Chinese graphite electrode sludge. Chin. Sci. Bull. 45, 1471-1476.

15. Weber, R., Gaus, C., Tysklind, M., Johnston, P., Forter, M., Hollert, H., Heinisch, E., Holoubek, I., Lloyd-Smith, M., Masunaga, S., Moccarelli, P., Santillo, D., Seike, N., Symons, R., Torres, J.P.M., Verta, M., Varbelow, G., Vijgen, J., Watson, A., Costner, P., Woelz, J., Wycisk, P., and Zennegg, M. (2008) Dioxin- and POP-contaminated sites-contemporary and future relevance and challenges. Environ. Sci. Pollut. Res. 15, 363-393.

16. Wang, X.L., Tao, S., Dawson, R.W., and Xu, F.L. (2002) Characterizing and comparing risks of polycyclic aromatic hydrocarbons in a Tianjin wastewater irrigated area. Environ. Res. 90, 201-206.

17. Zolezzi, M., Cattaneo, C., and Tarazona, J.V. (2005) Probabilistic ecological risk assessment of 1,2,4trichlorobenzene at a former industrial contaminated site. Environ. Sci. Technol. 39, 2920-2926.

18. China Administration of Quality Supervision (1998). The Specification for Marine Monitoring Part 5: Sediment Analysis. GB 17378.5-1998. Beijing, China.

19. Wang, T., Zhang, Z.L., Huang, J., Hu, H.Y., Yu, G., and Li, F.S. (2007) Occurrence of dissolved polychlorinated biphenyls and organic chlorinated pesticides in the surface water of Haihe River and Bohai Bay, China. Environ. Sci. 28, 730-735. [Chinese]

20. van Beelen, P., Verbruggen, E.M.J., and Peijnenburg, W.J.G.M. (2003) The evaluation of the equilibrium partitioning method using sensitivity distributions of species in water and soil. Chemosphere 52, 1153-1162

21. Wang, B., Yu, G., Huang, J., and Hu, H.Y. (2008) Development of species sensitivity distributions and estimation of $\mathrm{HC}_{5}$ of organochlorine pesticides with five statistical approaches. Ecotoxicology 17, 716-724.

22. Wang, B., Yu, G., Huang, J., Yu, Y.J., Hu, H.Y., and Wang, L.S. (2009) Tiered aquatic ecological risk assessment of organochlorine pesticides and their mixture in Jiangsu reach of Huaihe River, China. Environ. Monit. Assess. 157, 29 42.

23. Altenburger, R., Backhaus, T., and Boedeker, W. (2000) Predictability of the toxicity of multiple chemical mixtures to Vibrio fischeri: mixtures composed of similarly acting chemicals. Environ. Toxicol. Chem. 19, 2341-2347.

24. Altenburger, R., Nendza, M., and Schüürmann, G. (2003) Mixture toxicity and its modeling by quantitative structureactivity relationship. Environ. Toxicol. Chem. 22, 1900-1915.

25. Backhaus, T., Scholze, M., and Grimme, L.H. (2000) The single substance and mixture toxicity of quinolones to the bioluminescent bacterium Vibrio fischeri. Aquat. Toxicol. 49, 49-61.

26. Wang, B., Yu, G., Hu, H.Y., and Wang, L.S. (2007) Quantitative structure-activity relationship and mixture toxicity of substituted benzaldehydes to Photobacterium phosphoreum. Bull. Environ. Contam. Toxicol. 78, 503-509.

27. Wang, B. (2008) Ecological Risk Assessment Model of Persistent Organic Pollutants and Its Application [Doctoral dissertation]. Tsinghua University, Beijing.

28. Faust, M., Altenburger, R., Backhaus, T., Blanck, H., Boedeker, W., Gramatica, P., Hamer, V., Scholze, M., Vighi, M., and Grimme, L.H. (2003) Joint algal toxicity of 16 dissimilarly acting chemicals is predictable by the concept of independent action. Aquat. Toxicol. 63, 43-63.

29. Tianjin Oceanic Administration (2007) Communiqué of Marine Environmental Auality in Tianjin in 2006. Tianjin, China.

30. Zhao, L., Hou, H., Guo, P.Y., Zhou, Y.Y., and Li, F.S. (2009) Distribution of organochlorine pesticides in soils in Haihe River and Haihe Estuary area. Chin. Environ. Sci. 30, 543-550. [Chinese]

31. Qiu, X.H., Zhu, T., Yao, B., Hu, J.X., and Hu, S.W. (2005) Contribution of dicofol to the current DDT pollution in China. Environ. Sci. Technol. 39, 4385-4390.

32. USEPA (2009) U.S. EPA Toxics Release Inventory Reporting Year 2008 National Analysis: Summary of Key Findings. http://www.epa.gov/tri/tridata/tri08/national_analysis/pdr/TRI_key_findings_2008.pdf

33. Chen, C.S. (2005) Ecological risk assessment for aquatic species exposed to contaminants in Keelung River, Taiwan. Chemosphere 61, 1142-1158.

\section{This article should be cited as follows:}

Wang, B., Yu, G., Huang, J., Wang, T., and Hu, H. (2010) Probabilistic ecological risk assessment of OCPs, PCBs, and DLCs in the Haihe River, China. TheScientificWorldJOURNAL: TSW Environment 10, 1307-1317. DOI 10.1100/tsw.2010.126. 

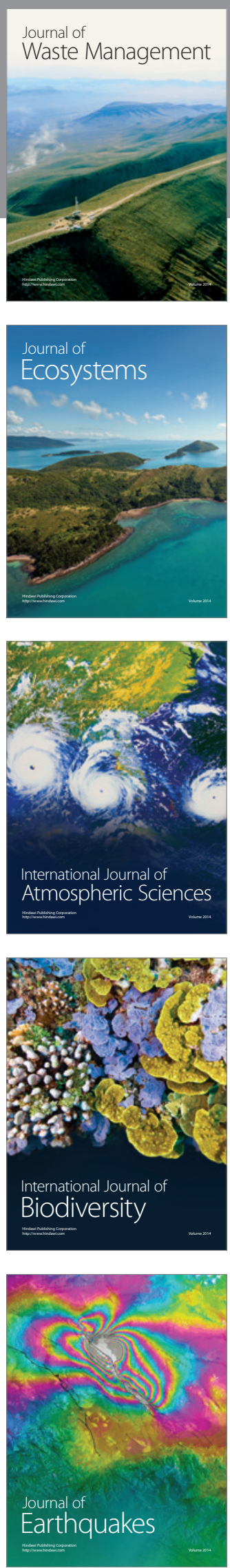
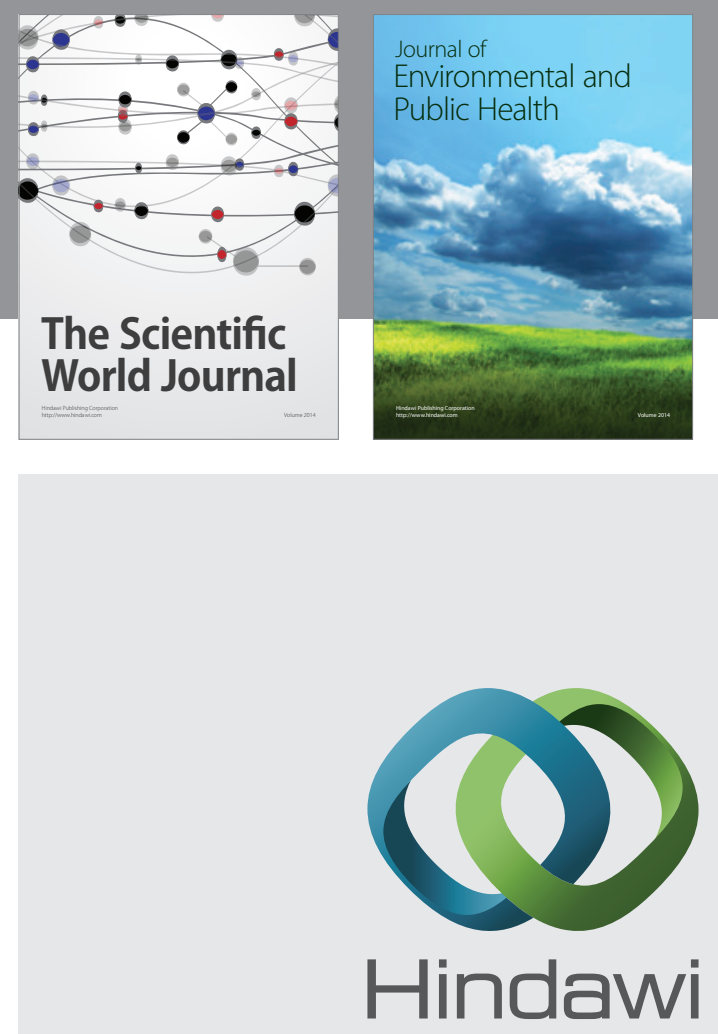

Submit your manuscripts at

http://www.hindawi.com
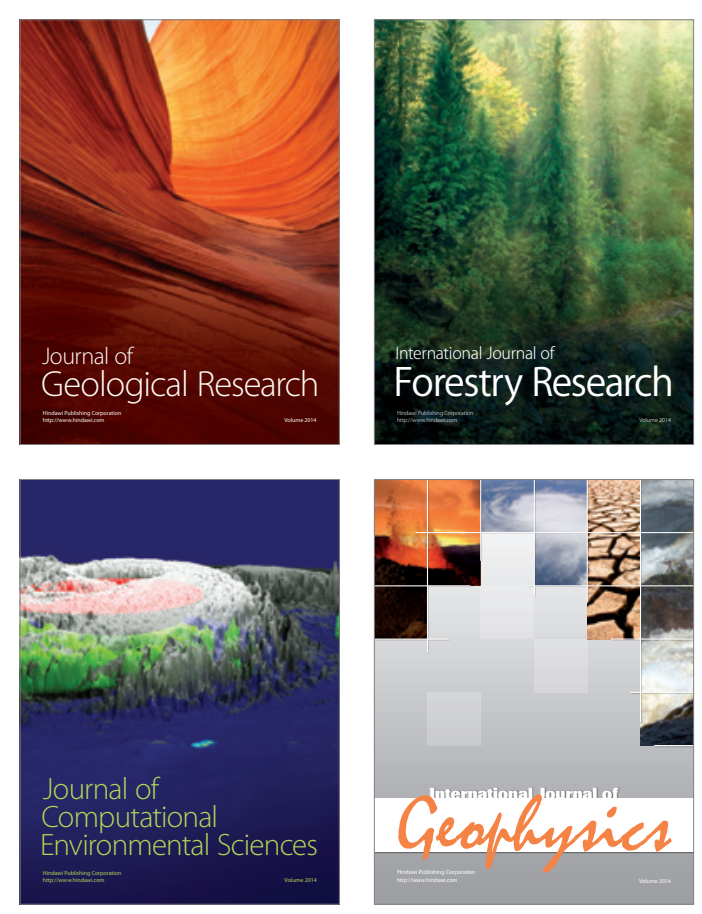
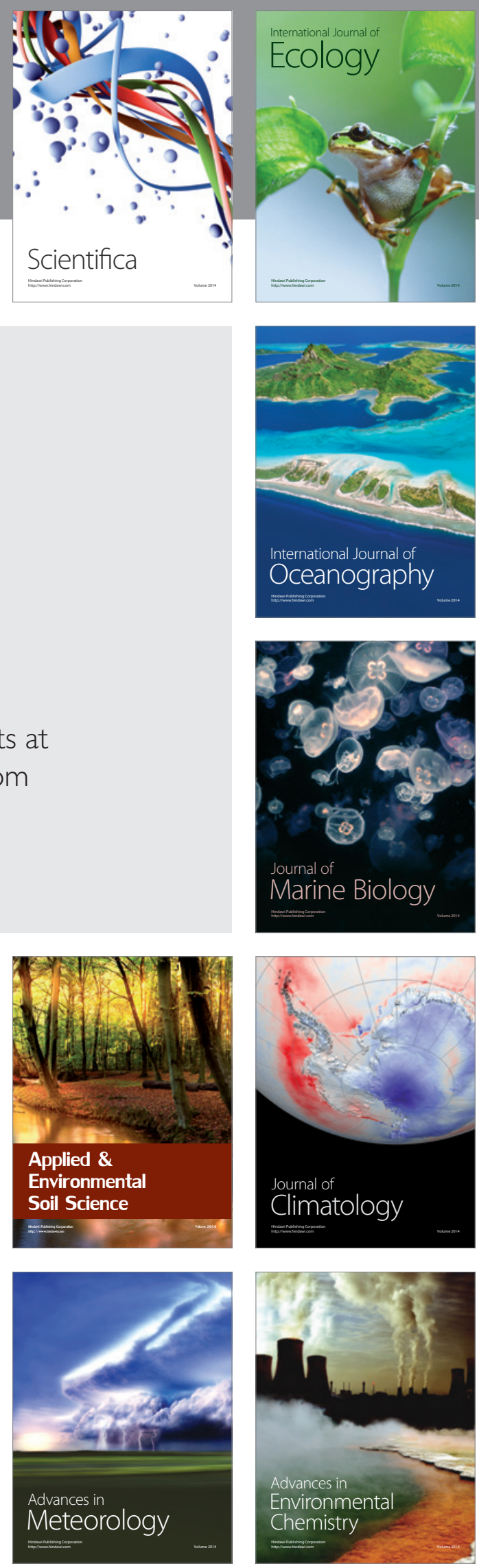